\title{
Analysis of the formation of fog and haze in North China Plain (NCP)
}

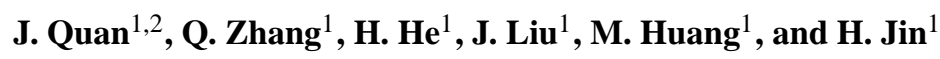 \\ ${ }^{1}$ Beijing Weather Modification Office, Beijing, China \\ ${ }^{2}$ Institude of Urban Meteorology, CMA, Beijing, China
}

Received: 14 March 2011 - Published in Atmos. Chem. Phys. Discuss.: 18 April 2011

Revised: 28 July 2011 - Accepted: 4 August 2011 - Published: 11 August 2011

\begin{abstract}
North China Plain (NCP) is one of the most populated and polluted regions in China. During the recent years, haze and fog occur frequently and cause severely low visibility in this region. In order to better understand the impact of aerosol particles on the formation of haze and fog, a long-term record of haze and fog occurrences in the past 56 yr (from 1954-2009) over NCP is analyzed. The results show that there are rapid changes in the occurrences of haze and fog over NCP. The occurrences of haze and fog were low during 1970-1980, and reached a maximum during 1981-1998. After 1999, the occurrences of haze and fog slightly decreased. There was a nonlinear relationship between the occurrences of haze and fog. When the occurrence of haze was lower than 40 days $\mathrm{yr}^{-1}$, the occurrence of fog was strongly proportional to the occurrence of haze. However, when the occurrence of haze was high (larger than 75 days $\mathrm{yr}^{-1}$ ), the occurrence of fog was not sensitive to the occurrence of haze. In order to better understand the relationship between the occurrences of haze and fog as well as the effect of aerosol particles on the formation of haze and fog, an in-situ field experiment was conducted during a period with a mixed occurrence of haze and fog. The analysis of the experiment suggests that there were considerably high aerosol concentrations during the measurement period with an averaged aerosol number concentration of $24000 \mathrm{~cm}^{-3}$. The measurement also shows that a large amount of aerosol particles can act as condensation nuclei to enhance the formation of fog droplets. As a result, a large amount of fog droplets $\left(>1000 \mathrm{~cm}^{-3}\right)$ with small size $(5-6 \mu \mathrm{m})$ were observed during the fog period, resulting in extremely low visibility (less than $100 \mathrm{~m}$ ).
\end{abstract}

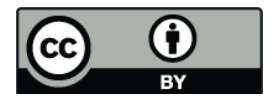

Correspondence to: $\mathrm{Q}$. Zhang (zqxxm_cn@sina.com)

\section{Introduction}

North China Plain (NCP) is located in northern coast China, and is surrounded by Taihang Mountains (at the west of NCP), Yanshan Mountains (at the north of NCP), and Bohai Sea (at the east of NCP) (see Fig. 1). NCP is one of the most populated and polluted regions in China. During the recent years, the rapid economical development has resulted in heavy atmospheric aerosol loadings in this region (Bian et al., 2007; Han et al., 2009; Tie et al., 2009; Zhang et al., 2009). The high aerosol concentrations induce severely environmental and climate problems. For example, aerosols have a direct effect for radiative forcing because they scatter (Charlson et al., 1987, 1992; Tegen et al., 2000) and absorb (Ramanathan and Vogelmann, 1997; Ramanathan et al., 2001; Jacobson, 2001) solar and infrared radiation in the atmosphere. In addition to the climate effect, aerosols also affect human health and visibility (Tie et al., 2009; Wu et al., 2005; Deng et al., 2008). Moreover, aerosol particles can act as cloud condensation nuclei (CCN) to affect the formation of cloud and fog.

In this study, a long-term trend of haze and fog (from 1954 to 2009) in the NCP region is analyzed. In addition to the trend analysis, a field experiment was conducted during an extreme low visibility period (from 5 to 8 November 2008) in NCP. In order to better understand the characteristics of haze and fog in the NCP region, meteorological parameters, the size distributions and number concentrations of aerosol particles and fog droplets were simultaneously measured during the experiment. Both the trend data and the experiment result provide valuable information to study several important characteristics of haze and fog, including; (1) the evolution of haze and fog occurrences in the past $56 \mathrm{yr}$; (2) the relationship between the occurrences of haze and fog; (3) the impact of aerosol particles on the formation of haze and fog; and (4) the impact of haze and fog on visibility. 
Table 1. The criterions of fog, mist and haze by visibility and $\mathrm{RH}$

\begin{tabular}{|c|c|c|c|}
\hline Criterion & Fog & Mist & Haze \\
\hline WMO No. 266, 1984 & vis $<1 \mathrm{~km}$; RH generally near $100 \%$ & RH Generally lower than $100 \%$ & $\mathrm{RH}<$ about $80 \%$ \\
\hline WMO No. 8, 1996 & vis $<1 \mathrm{~km}$; & vis $\geq 1 \mathrm{~km}$; high $\mathrm{RH}$ & $\begin{array}{l}\text { vis }>1 \mathrm{~km} \text {; } \mathrm{RH} \text { is less than } \\
\text { a certain percentage, e.g. } 80 \%\end{array}$ \\
\hline WMO No. 782,2005 & vis $<1 \mathrm{~km}$ & vis $\approx 1 \sim 5 \mathrm{~km} ; \mathrm{RH}>95 \%$ & vis $\leq 5 \mathrm{~km}$; \\
\hline $\begin{array}{l}\text { Handbook of Aviation Meteorology, } \\
\text { UKMO, } 1994\end{array}$ & vis $<1 \mathrm{~km}$; RH generally near $100 \%$ & vis $\geq 1 \mathrm{~km} ; \mathrm{RH} \geq 95 \%$, generally $<100 \%$ & $\mathrm{RH}<95 \%$ \\
\hline The work of Vautard et al. (2009) & vis $\leq 1 \mathrm{~km}$; & vis $\leq 2 \mathrm{~km}$ & vis $\leq 5 \mathrm{~km}$ \\
\hline The work of Wu et al. (2006) & $\mathrm{RH} \geq 90 \%$ & $\mathrm{RH} \geq 90 \%$ & vis $<10 \mathrm{~km} ; \mathrm{RH}<90 \%$ \\
\hline
\end{tabular}

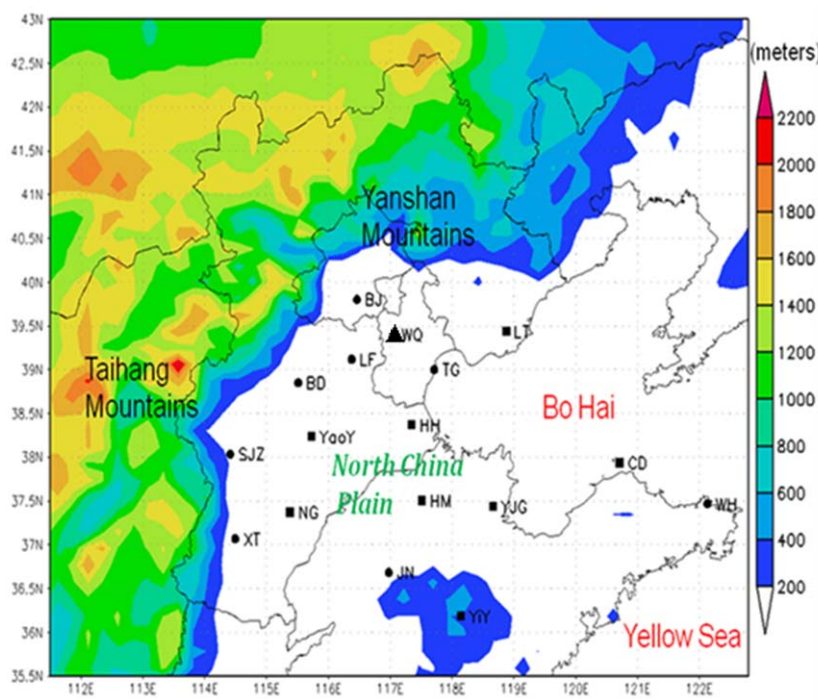

Fig. 1. The topographic map of NCP and the location of visibility observation sites, location of the 16 measurement sites (circleurban; square-rural) and a field experiment station (triangle).

The paper is organized as the following way. In Sect. 2, we show the analysis of the long-term haze and fog trends. In Sect. 3, we describe the field experiment, including the instruments and the results of the experiment.

\section{A long-term trend of haze and fog in NCP}

The occurrences of haze and fog were observed at 16 meteorological sites in the NCP region from 1954 to 2009. The measured haze and fog occurrences were based on the observations of visibility and relative humidity $(\mathrm{RH})$ and the criterion of WMO, UKMO and method suggested by Vautard et al. (2009) and Wu (2006) (Table 1). The data of visibility and $\mathrm{RH}$ are from the history observations at weather stations of China Meteorological Bureau. The data include observations at 02:00 local time (LT), 08:00 LT, 14:00 LT and 20:00 LT. In this study the observations at 08:00 LT were selected since 08:00 LT is the rush hour when fogs appear. In this work, the criterions of fog and haze events were set as: (1) for the occurrence haze events, the following conditions should be satisfied, i.e., visibility $\leq 5 \mathrm{~km}$ and RH $95 \%$. Under such conditions, the concentrations of aerosol particles, especially fine particles, are generally high (Deng et al., 2008); (2) for the occurrence of fog events, including mist events in this study since fog and mist were not distinguished clearly in China, the following conditions need to be satisfied, i.e., visibility $\leq 2 \mathrm{~km}$ and $\mathrm{RH} \geq 95 \%$. They also explain that the current instruments of $\mathrm{RH}$ have at least $5 \%$ low-bias to accurately measure the value of $\mathrm{RH}$ when the value of $\mathrm{RH} \geq 95 \%$. As a result, the $\geq 95 \%$ measurement of $\mathrm{RH}$ often implies that the saturation of water vapors $(\mathrm{RH} \geq 100 \%)$ may occur in the atmosphere. Based on the above definitions, a longterm record of haze and fog occurrences are obtained in 16 measurement stations in the NCP region (see Fig. 1). These 16 measurement sites are classified into 8 urban and 8 rural sites (see Fig. 2). In general, the urban sites are located inside cities with higher aerosol emissions, and the rural sites are located outside of cities with lower aerosol emissions.

Figure 2 shows that the long-term variations of haze and fog occurrences between the urban and the rural sites were very different, mainly resulting from the different situations of economical development in different sites. For these urban sites (Beijing (BJ), Shijiazhuang (SJZ), Baoding (BD), and Jinan $(\mathrm{JN})$ ), they are located in relatively large cities, and the rapid economical development started from the late 1970s. As a result, there was a rapid increase in the occurrence of haze (OHAZ) from the late of 1970 s to the early of $2000 \mathrm{~s}$. During this period, OHAZ increased from 20-50 to 150200 days $\mathrm{yr}^{-1}$. At the Tanggu (TG) site (urban), the increase of OHAZ occurred from the early 2000s (when this region became a special economical zone) to the present, indicating that the timing of economical development plays important roles for OHAZ. Other urban sites (Xingtai (XT), Weihai (WH), and Langfang (LF)) are located in relatively small cities, and the increase of OHAZ was smaller than the value at large cities. For the rural sites, the increase of OHAZ was generally smaller than values at the urban sites. For example, compared to 150-200 days $\mathrm{yr}^{-1}$ in the large cites, OHAZ increased to $40-80$ days $\mathrm{yr}^{-1}$ in the 2000 s at the 7 rural sites (except for the YiY site). 


\section{urban site}
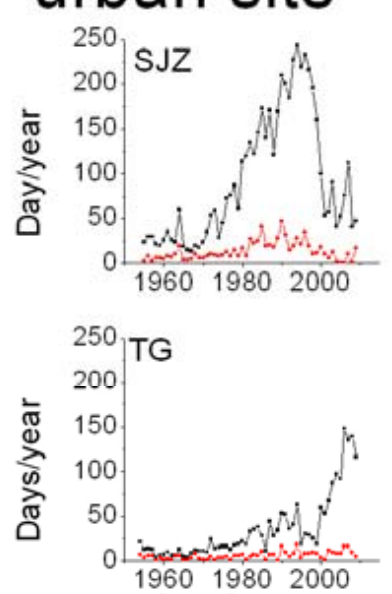

\section{rural site}
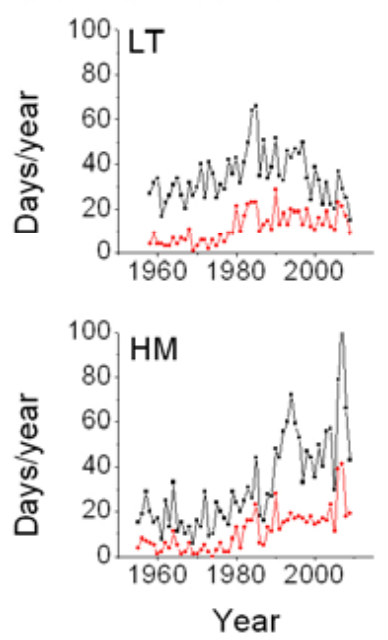
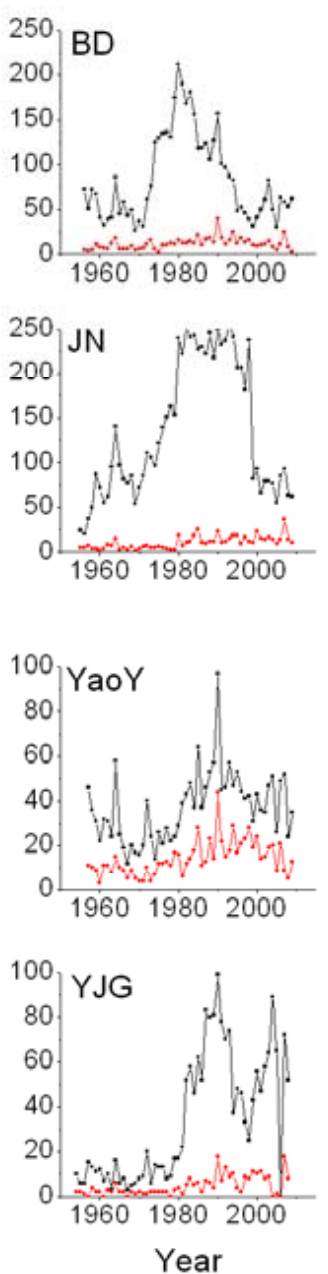
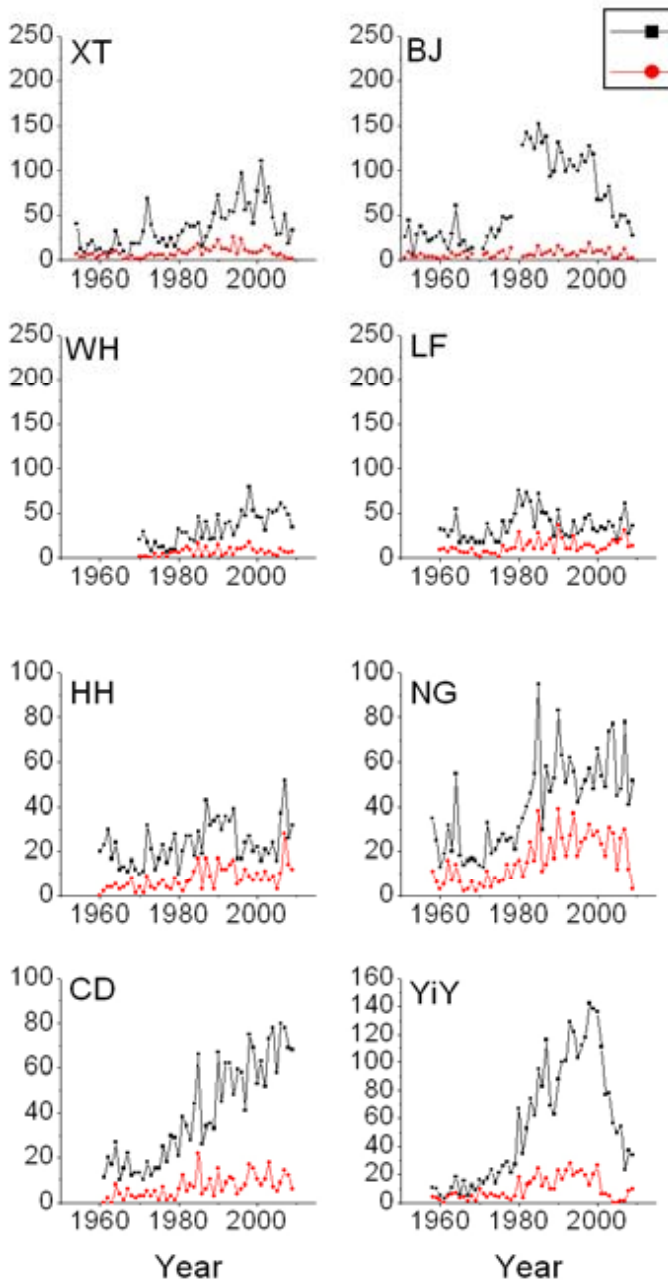

Fig. 2. The occurrences of haze (black lines) and fog (red lines) over NCP during 1954-2009.

On average, the evolution of OHAZ at the urban sites can be categorized to 4 periods (shown in Fig. 3). Between 1954 and 1970, the OHAZ days were very low $\left(31.3 \pm 22.9\right.$ days $\left.\mathrm{yr}^{-1}\right)$, indicating that there was generally good visibility over NCP during this period. This period is defined as period-1. Between 1971 and 1980, the OHAZ days rapidly increased, reaching to $103.3 \pm 90.2{\text { days } \mathrm{yr}^{-1} \text { in }}^{-1}$ 1980. This is a transition period from good visibility to poor visibility in NCP, which is defined as period-2. Between 1981 and 1998, the OHAZ days remained in a constant high value $\left(100.5 \pm 78.1\right.$ days $\left.\mathrm{yr}^{-1}\right)$, which is defined as period-3. Finally, between 1999 and 2009, the OHAZ days slowly decreased, falling to $52.3 \pm 28.8$ days $\mathrm{yr}^{-1}$ in 2009 , which is defined as period- 4 .

The OHAZ days at the rural sites were lower than the values at the urban sites and had a time lag compared to the evolution at the urban sites. For example, before 1980, the OHAZ days remained in a constant value (18.9 \pm 8.7 days $\left.\mathrm{yr}^{-1}\right)$, which was lower than values at the urban sites $\left(38.8 \pm 30.7\right.$ days $\left.\mathrm{yr}^{-1}\right)$. At the rural sites, the OHAZ days started to increase in 1980s rather than 1970 s at the urban sites. For example, between 1980 and 1985, the OHAZ days increased from $30.2 \pm 17.8$ to $65.1 \pm 22.5$ days $\mathrm{yr}^{-1}$. After 1985, the OHAZ days remained $52.3 \pm 25.3$ days $\mathrm{yr}^{-1}$.

Previous studies suggested that OHAZ is closely correlated to the concentrations of aerosol particles. For example, according to the study by Deng et al. (2008), the aerosol particle concentrations in large cities of China increased rapidly from 1970s, and the rapid increase in aerosol particles produced the increase in the OHAZ days. Because part of aerosol particles can also act as condensation nuclei of fog droplets, therefore the increase of aerosol particles concentration could affect of the microphysical characteristic of fog droplets. 

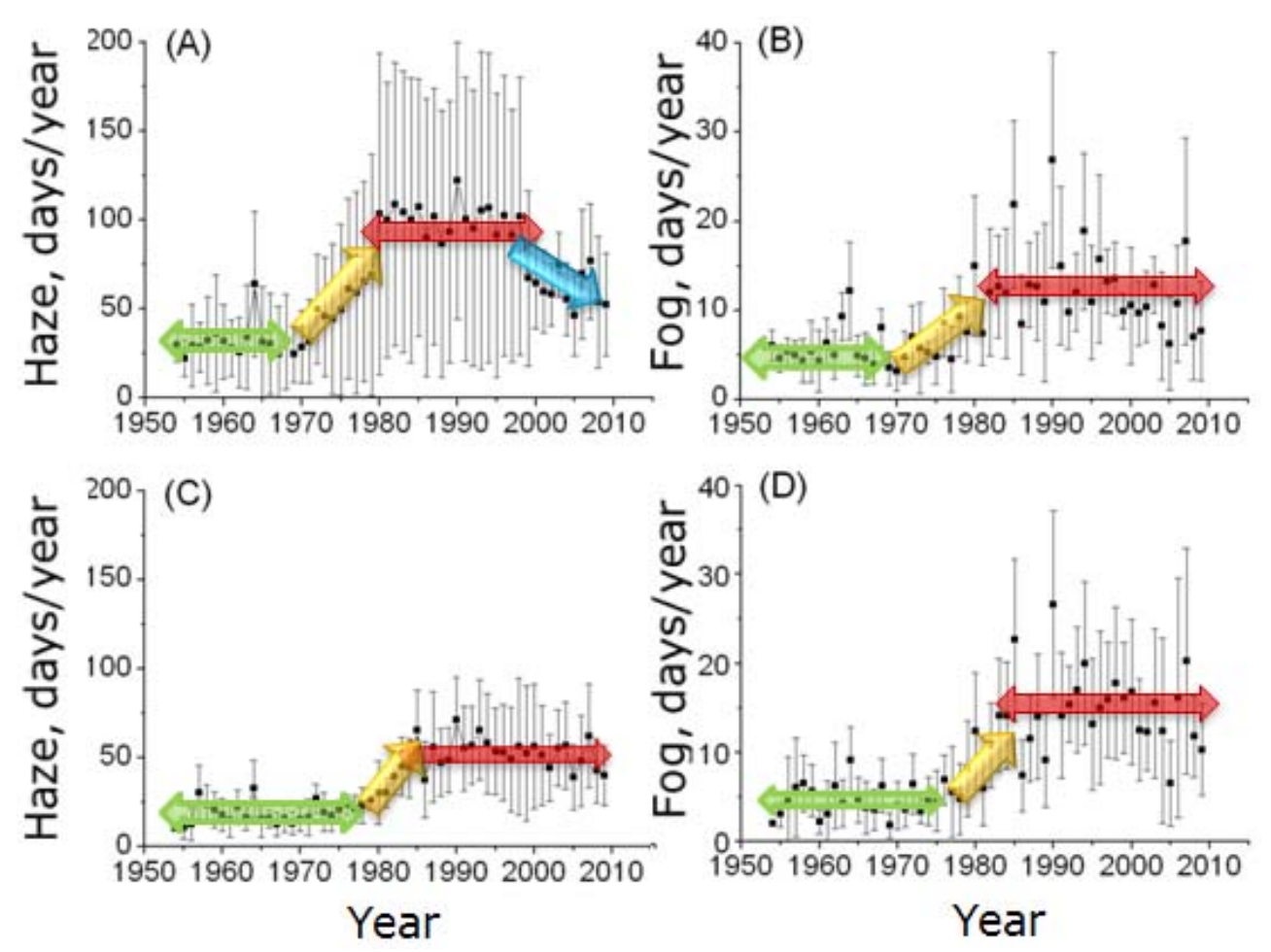

Fig. 3. Evolution of average haze day occurrences at urban sites (A) and rural sites (C), and average fog day occurrences at urban sites (B) and rural sites (D) over the NCP region, the bars is standard deviation.

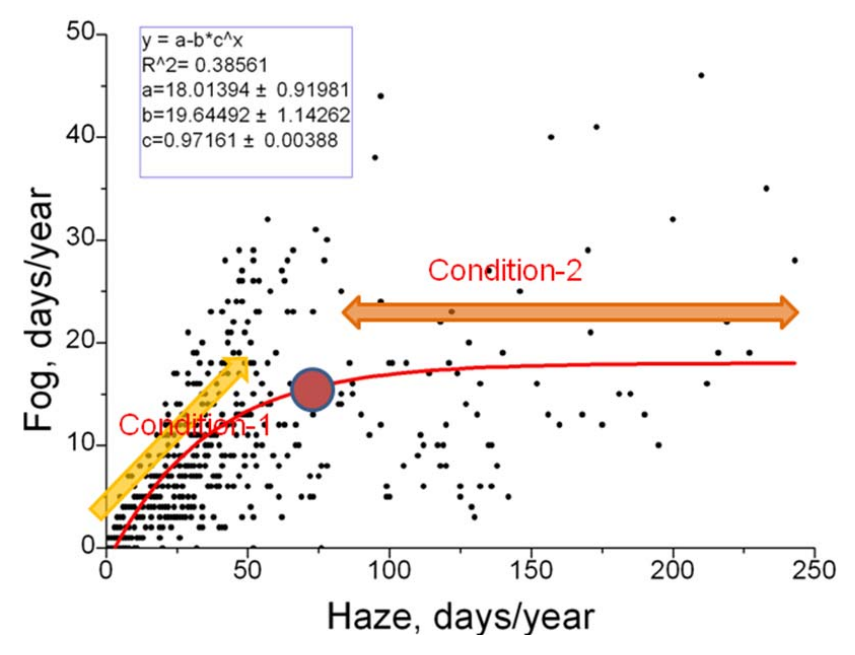

Fig. 4. The correlation between averaged fog and haze day occurrences.

Figure 3 shows also the evolution of the occurrence of fog (OFOG) days at both the urban and rural sites. The trend of OFOG days shows very similar characteristics to the trend of OHAZ days. Between 1954 and 1975, the OFOG days were very low (5.6 \pm 2.7 days $\left.\mathrm{yr}^{-1}\right)$. Between 1975 and 1982, the OFOG days increased rapidly, reaching to $12.0 \pm 9.2$ days $_{\mathrm{yr}^{-1}}$ in 1982 . Finally, between 1983 and 2009, the OFOG days remained in a constant high value $\left(11.4 \pm 6.9\right.$ days $\left.y^{-1}\right)$. The OFOG days at rural sites were similar to the evolution at the urban sites,. Figures 3 illustrates that there is a similarity between the trends of OHAZ and OFOG, showing the influence of aerosol particles to the formation of both haze and fog.

The detailed relationship between OHAZ and OFOG shows in Fig. 4. The result indicates that there was a nonlinearity relationship between the OHAZ and OFOG days.

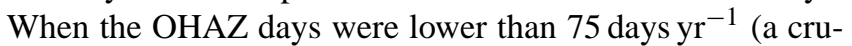
cial value), the OFOG days were strongly dependent upon the OHAZ days (Condition-1). When the OHAZ days exceeded the crucial value, the OFOG days were not sensitive to the OHAZ days (Condition-2). The occurrence of haze and fog was influenced by weather conditions, such as static stable weather condition and abundant vapors (for fog). In addition, the aerosol concentration might also be a factor that influences the OFOG days. Under a constant liquid water content during fog events, the higher of fog droplets concentration were formed, with smaller of fog droplets size, leading to a longer of resident time of fog event due to slower gravitational settling velocity. Therefore, the increase of aerosol concentration tends to increase the OFOG days (Condition-1 in Fig. 4). However, when the aerosol particles exceeded a certain values, there were no enough water content to form more fog droplets (Zhang et al., 2011), and the increase of aerosol concentration would have no 
further contribution on OFOG days (Condition-2 in Fig. 4). As shown in Fig. 3, the OFOG days at urban stations were almost constant (12 days) after 1980's, which were not similar as the trend of OHAZ days.

Above analysis shows that aerosol particles may have important impacts on both the haze and fog formation, leading to change in the visibility over NCP. However, the above analysis only highlights a statistical result. The detailed physical processes which control the interaction between aerosol particles and the OHAZ/OFOG days cannot be provided by the above analysis. In order to better understand the detailed information regarding the impact of aerosol particles on the formation of haze and fog, a field measurement was conducted and the results are analyzed.

\section{Analysis of experiment (a case study)}

\subsection{Instruments of the Experiment}

Several instruments were deployed during the field experiment at Wuqing (WQ) (39.4 lat and 117.05 lon), which is located in the NCP between the two Megacities of Beijing and Tianjin. The field study, focusing on microphysical characteristics of aerosol particles and fog droplets, were carried out from November to December 2009. The data used in this work includes the size distribution of aerosol particles and fog droplets, meteorological parameters (ambient air temperature $(T)$, relative humidity $(\mathrm{RH})$, and air pressure $(P))$, and visibility.

The ambient aerosol sample passes through a silica gel diffusion drier, maintaining a relative humidity $(\mathrm{RH})$ below $40 \%$. The aerosol sample is then led into the air-conditioned measurement container with a temperature around $20^{\circ} \mathrm{C}$. For fog droplet, it is observed at ambient atmosphere.

The aerosol number distribution in different size bins (10$662 \mathrm{~nm}$ ) were obtained by a Scanning Mobility Particle Sizer (SMPS, Model 3936, TSI, USA) with a time resolution of five minutes. The SMPS consist mainly of Differential Mobility Analyzer (DMA, Model 3081) and Condensation Particle Counter (CPC, Model 3772). The DMA sheath and sample flows were $3 \mathrm{lpm}$ and $0.3 \mathrm{lpm}$, respectively.

Fog number size distributions ( $2-32 \mu \mathrm{m})$ were obtained by Droplet Measurement Technology (DMT) of fog measuring device (FMD; FM-100). The LWC of fog is calculated on the volume concentration of fog droplets observed by FM- 100 . The structure of fog is obtained by Microwave radiometers (MP-3000A) from Radiometrics Corporation.

\subsection{Background of meteorological conditions during experiment}

A dense fog/haze event occurred over the NCP region between 5 and 8 November, 2009, producing extremely poor visibility. The measured data during this event is intensively studied (as a case study). During the event, both fog and haze

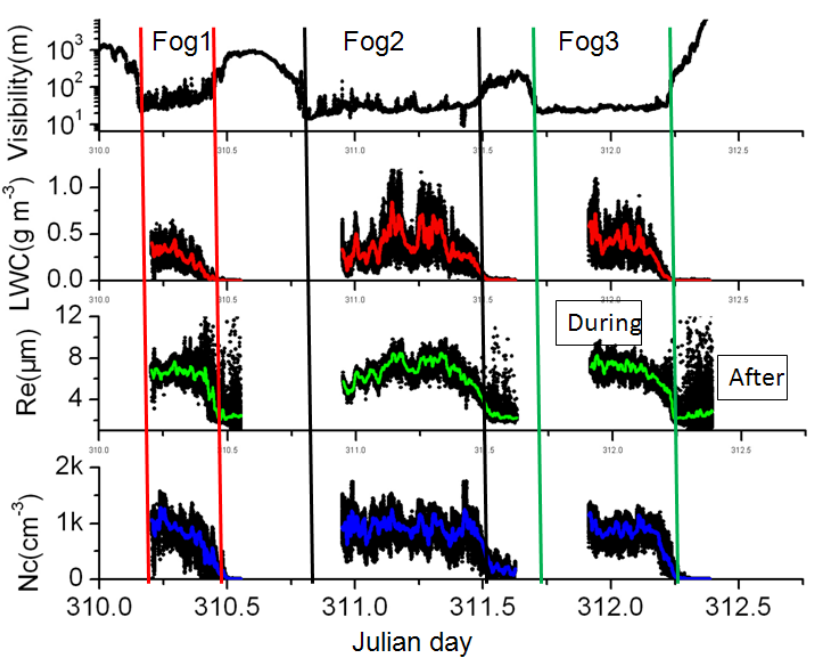

Fig. 5. The characteristics of fog droplets, including fog droplet number concentration $(\mathrm{Nc})$, effective radius $(\mathrm{Re})$, and liquid water content (LWC).

occurred, and a cascade formation of fog appeared. Based on the durations of fog occurrence in the event, three fog periods are found according to the observed relative humidity (RH), ambient temperature, fog liquid water content (LWC), and the range of visibility. The first fog period (Fog-1) occurred from 03:45 LT to 10:42 LT, 6 November. The second fog period (Fog-2) appeared from 19:10LT, 6 November to 12:27 LT, 7 November, and the third fog period (Fog-3) occurred from 16:29LT, 7 November to 05:40 LT, 8 November (see Fig. 5). During this fog/haze event, the NCP region was under the effect of a weak low pressure system with calm winds. The average surface wind speed was only $1.1 \mathrm{~m} \mathrm{~s}^{-1}$ during the event. However, in the late of 8 November, the low pressure system moved out of the NCP region, and the wind speed increased to about $4 \mathrm{~m} \mathrm{~s}^{-1}$ at the end of the event. The averaged surface temperature was low $\left(6.8 \pm 3.4^{\circ}\right)$ during the event. At the end of the event, it increased to about $15^{\circ}$, and the visibility range significantly increased.

Although the visibility is considerably low (with an averaged visibility of $414 \mathrm{~m}$ ) during the entire duration of the event, the visibility during the 3 fog periods was significantly lower than the average visibility of the event. For example, during the Fog-1, Fog-2, and Fog-3 periods, the visibilities were only 85,30 , and $27 \mathrm{~m}$, respectively. There was lack of measurement of RH during the Fog-3 period. As a result, the RH values were only available during the Fog- 1 and Fog-2 periods, with RH values of $95-96 \%$. With accounting for about $4-5 \%$ low bias of the RH due to the shortage of the instruments (Guo et al., 1994), the RH during the Fog-1 and Fog-2 periods should be considered to reach to a supersaturation point, leading to the formation of fogs. In addition to relative humidity, during the 3 fog periods, the visibility was rapidly (in a time scale of $2 \mathrm{~min}$ ) reduced from 345 to 

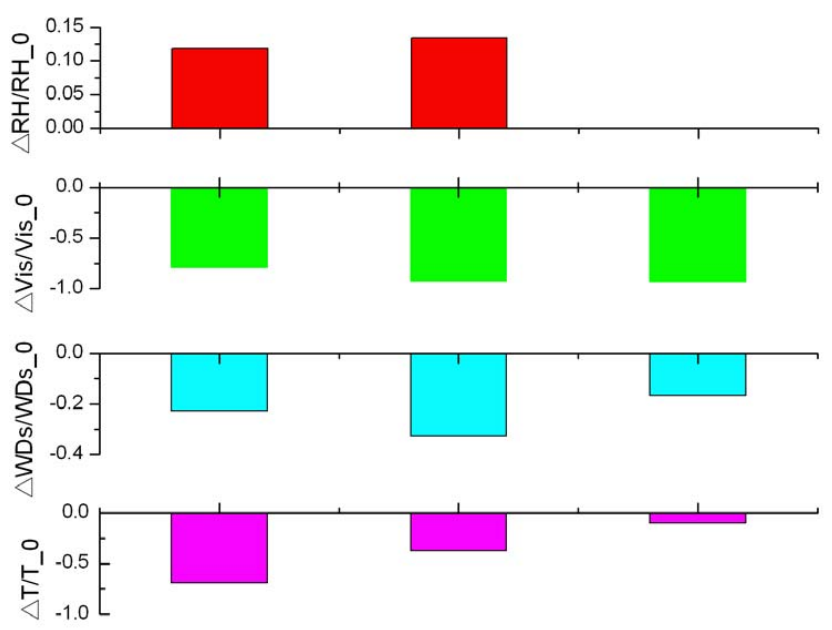

$\begin{array}{lll}\text { Fog1 Fog2 Fog3 } & \text { Fog }\end{array}$

Fig. 6. The anomalies of the visibility, surface temperature, relative humidity, and surface wind speed during the three fog period to the averaged value of the event.

36,199 to 56 , and 187 to $42 \mathrm{~m}$, respectively at the beginning of the fog events. The LWC appeared during the fog periods, with averaged values of $0.201 \pm 0.145,0.308 \pm 0.224$, and $0.294 \pm 0.216 \mathrm{~g} \mathrm{~m}^{-3}$ during the 3 fog periods, respectively. The number concentrations $(\mathrm{Nc})$ of fog droplets were about $715 \pm 352,782 \pm 331$, and $683 \pm 368 \mathrm{~cm}^{-3}$ during the Fog-1, Fog-2, and Fog-3 periods, respectively.

In order to analyze the causes of the 3 fogs, the anomalies of the visibility, surface temperature, relative humidity, and surface wind speed to the averaged values of the fog/haze event ( 5 to 8 November) during the three fog periods are calculated and shown in Fig. 6 . The result indicates that during the 3 fog periods, the surface temperature was lower by $69 \%$, $37 \%$, and $10 \%$ than average temperature, and the surface wind speed was lower by $23 \%, 33 \%$ and $17 \%$ than average value for the Fog-1, Fog-2, and Fog-3 periods, respectively. These variabilities of temperature, wind speed, and humidity were favorable for the formation of fog, resulting in the 3 cascade fog periods.

A noticeable condition during the fog periods is that there were extremely high aerosol loadings during the measurement period. For example, averaged number and mass concentrations of aerosol were $24000 \mathrm{~cm}^{-3}$ and $160 \mu \mathrm{g} \mathrm{m}^{-3}$ (with aerosol diameter of 10-662 nm), respectively. These values are about 10 times higher than that of four European cities (Puustinen et al., 2007), and could lead to heavy haze event and enhancement of fog formation (Deng et al., 2008; Zhang et al., 2011).

\subsection{Characteristics of fog droplets}

The above analysis shows that under high aerosol condition, the formation of fogs was frequently occurred, indicating that the high aerosol loadings have important effects on the formation of fog. In order to study the role of heavy aerosol loading on fog formation, the detailed microphysical information of fog droplets is analyzed. The cloud condensation nuclei $(\mathrm{CCN})$ were also observation by DMT CCN counter during the field experiment, the detailed information of the instrument is described by Deng et al. (2011). The measured $\mathrm{CCN}$ number concentration (Nc) was about $6600 \mathrm{~cm}^{-3}$ (with a supersatuation of $0.2 \%$ ), indicating the aerosol number concentration (Na) (about $24000 \mathrm{~cm}^{-3}$ ) was about 3 times higher than the CCN particles, which can provide enough condensation nuclei for the formation of fog droplets.

Figure 7 shows the Nc and effective radium (Re) versus LWC in the three fog events. It shows that the Nc and $\mathrm{Re}$ of fog droplets increase with the enhancement of LWC. For example, the averaged values of Re and $\mathrm{Nc}$ are $6.1 \mu \mathrm{m}$ and $769 \mathrm{~cm}^{-3}$ when LWC is $0.2 \mathrm{~g} \mathrm{~m}^{-3}$, while their values increase to $7.8 \mu \mathrm{m}$ and $1054 \mathrm{~cm}^{-3}$ when LWC increases to $0.6 \mathrm{~g} \mathrm{~m}^{-3}$. The detailed distribution of droplet size provides more information during different stages of fog periods. Figure 8 shows that during the middle stage of Fog-2 (from 03:00 LT to 08:00 LT, 7 November), for the droplet size of $5 \mu \mathrm{m}$ (radium), $d \mathrm{Nc} / d \log D$ reached a maximum value of $1300 \mathrm{~cm}^{-3} \mu \mathrm{m}^{-1}$. The value of $d \mathrm{Nc} / d \log D$ was then sharply decreased with the increase of size of droplets. For example, the value of $d \mathrm{Nc} / d \log D$ reduced to $130 \mathrm{~cm}^{-3} \mu \mathrm{m}^{-1}$ when the droplet radius increased to $15 \mu \mathrm{m}$. At the late stage of Fog-2, (from 11:00 LT to 12:00 LT, 7 November), the larger droplets were significantly decreased due to the faster gravity settling. For instance, for the size of droplet of $12 \mu \mathrm{m}$, the value of $d \mathrm{Nc} / d \log D$ was $250 \mathrm{~cm}^{-3} \mu \mathrm{m}^{-1}$ at the middle stage, but it was rapidly decreased to $20 \mathrm{~cm}^{-3} \mu \mathrm{m}^{-1}$ at the late stage of Fog-2. However, for the size of droplet of $2-4 \mu \mathrm{m}$ which the gravity settling velocity is significantly smaller than the large droplets, the values of Nc were remained the same values compared with the values at the middle stage, indicating that gravity settling of droplets plays important roles when the radius of droplets are larger than $5 \mu \mathrm{m}$.

In order to analyze the influence of heavy aerosol loading on the microphysical information of fog droplets, we compare our result with that of Gultepe et al. (2009), who analyzed the measurement in Toronto, Canada. In their observation, the $\mathrm{Nc}$ of fog droplet is only about $100 \mathrm{~cm}^{-3}$, the Re reached $15 \mu \mathrm{m}$ as LWC is $0.2 \mathrm{~g} \mathrm{~m}^{-3}$. While in our observation, the $\mathrm{Nc}$ of fog droplet is about $1000 \mathrm{~cm}^{-3}$, the Re is just about $6 \mu \mathrm{m}$ as LWC is $0.2 \mathrm{~g} \mathrm{~m}^{-3}$. The above analysis indicated that heavy aerosol loading in NCP results in the high number concentration of small fog droplets. Because the size of droplet affects their resident time in the atmosphere, the high aerosol concentration in NCP could cause longer duration of fog event. Based on observed 

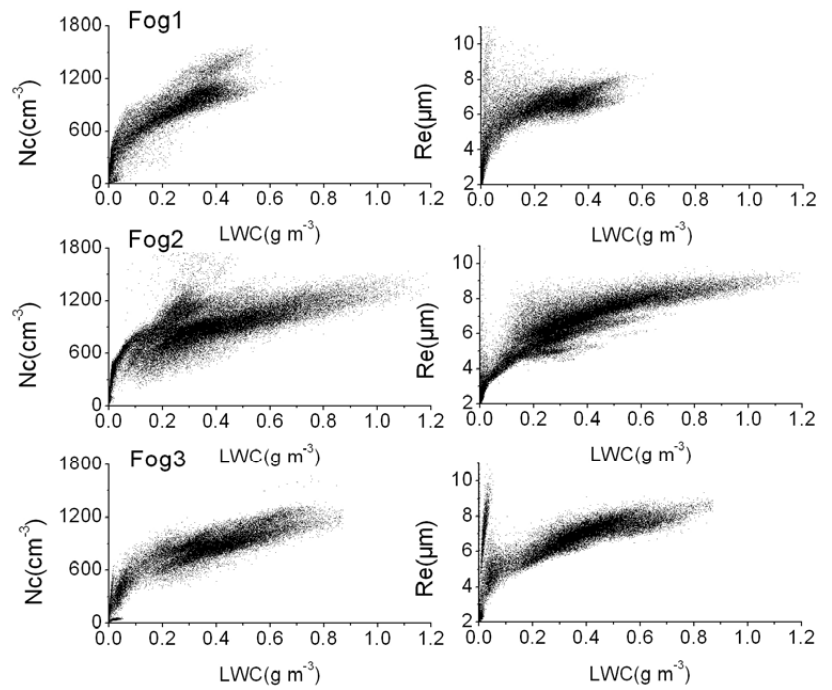

Fig. 7. The Nc and effective radium (Re) versus LWC in the three fog events.

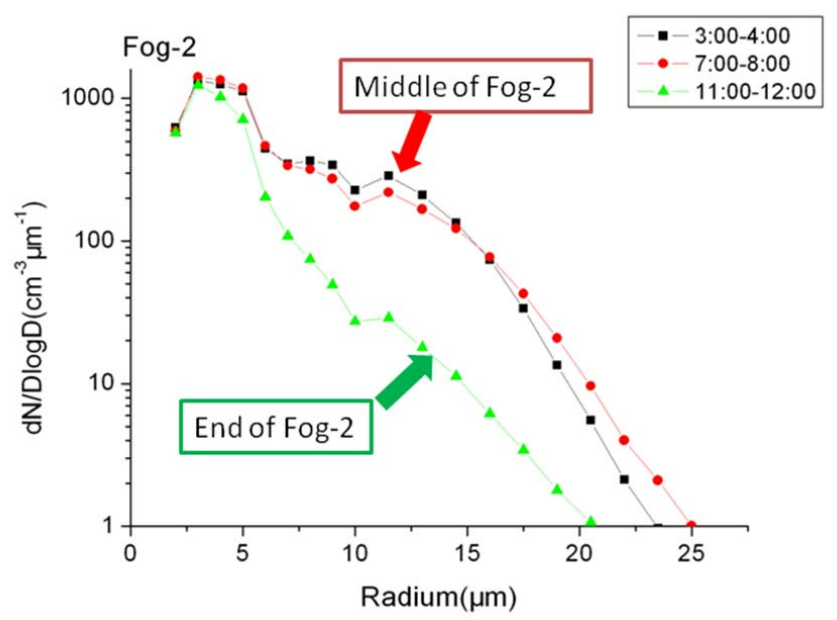

Fig. 8. The evolution of the size distribution of fog droplets in the Fog-2 period.

microphysical information of fog droplets, the resident time $(T d)$ of fog droplets due to gravity settlement velocity is calculated. During the Fog-2 period, with measured Re value and assumed height of fog layer of $1500 \mathrm{~m}$, the calculated Td is about $40 \mathrm{~h}$, while the cool air for maintaining the formation of fog is about $6-8 \mathrm{~h}$. As a result, the evaporated water vapors were mostly suspended in the atmosphere, and formed fog again when temperature decreased. The above analysis suggested that the large amount of aerosol particles in NCP tend to increase number concentration of fog droplets, but decrease their size. As a result, the fog droplets suspend in a longer time in the atmosphere, causing a longer duration of fog event or a cascade formation of fogs.

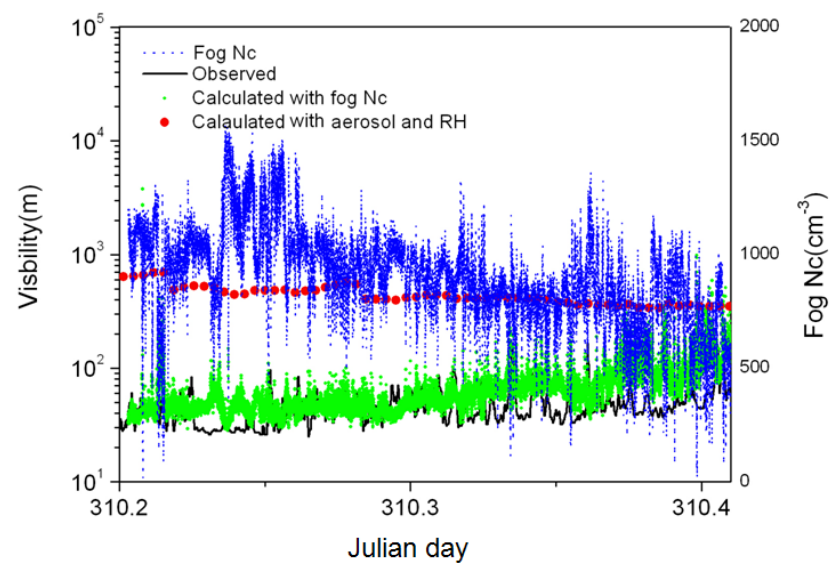

Fig. 9. The calculated visibility during the Fog-1 period based upon the measured concentrations of fog droplets and aerosol particles.

\subsection{Effect of fog and aerosol on visibility}

In order to understanding the effect of aerosol particles and fog droplets on visibility, the range of visibility is calculated based on the observed microphysical properties of fog droplets and aerosol particles. The method for calculating the range of visibility is as the follows (Seinfeld and Pandis, 1998):

$\mathrm{VIS}=3.912 / \beta$

Where $\beta$ represents total optical extinction coefficient due to cloud droplets and aerosol particles. The impacts of gas phase molecules on visibility include Rayleigh scattering of air, and the absorptions of $\mathrm{O}_{3}, \mathrm{NO}_{2}$, and $\mathrm{SO}_{2}$ of solar radiation are small compared with the droplets and particles under heavy aerosol loading conditions. As a result, their effects on visibility are ignored in this study (Deng et al., 2008).

Figure 9 shows the calculated visibility during the Fog1 period based upon the measured concentrations of fog droplets and aerosol particles. The result shows that the measured visibility was extremely low (30 to $60 \mathrm{~m}$ ) during the Fog-1 period. In order to estimate the individual contributions of fog droplets and aerosol particles to the measured low visibility, the individual contribution of fog droplets and aerosol particles to the range of visibility is calculated according to Eq. (1). For example, with considering the solo effect of aerosol particles on visibility, the calculated visibility ranges from 300-600 $\mathrm{m}$ with considering the hygroscopic growth of aerosols (the rate of hygroscopic growth from Yan et al., 2009). Although the visibility is very low due to the heavy aerosol loadings, the calculated values are significantly higher than the measured result $(30-60 \mathrm{~m})$. The calculated visibility also shows that the visibility has a slightly decrease trend from the beginning of the fog $(600 \mathrm{~m})$ to the end of the fog $(300 \mathrm{~m})$, while the observed visibility has an increase trend from the beginning of the fog $(30 \mathrm{~m})$ to the end 


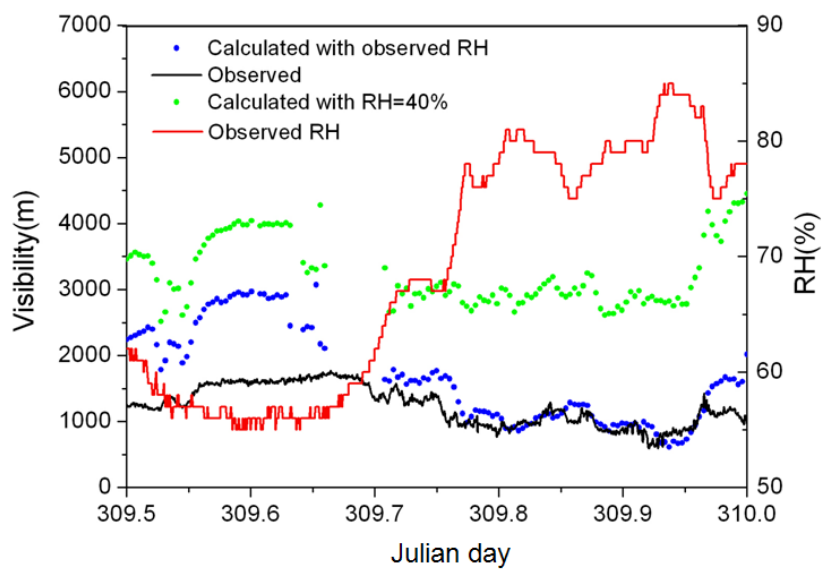

Fig. 10. The calculated visibility prior the Fog-1 period based upon the measured concentrations of aerosol particles.

of the fog $(60 \mathrm{~m})$. Both the inconsistencies (range and trend of visibility) suggest that the measured extreme low visibility (less than $100 \mathrm{~m}$ ) cannot be resulted only from aerosol particles. When the effect of fog droplets are taken into account for the calculation of visibility, the calculated visibility is fairly consistent to the measured values (see Fig. 9). Furthermore, the calculated visibility trend also agrees with the observed trend, showing that the visibility slightly increases at the end of the fog period.

Figure 10 illustrates the effect of hygroscopic growth of aerosols on visibility. During the event, there was several haze periods which occurred before or after the formation of the 3 fog periods. During these haze periods (non-fog periods), heavy aerosol loadings played important roles for the reduction of visibility due to the scattering and absorbing properties of aerosol particles (Charlson et al., 1987; Jacobson, 2001; Deng et al., 2008). In addition to the direct radiative effect on visibility by dry aerosol particles, the hygroscopic growth of aerosol particles also play an important role in controlling the calculation of visibility. The hydrophilic aerosol particles (such as sulfate, sea salt, etc) increase the size of particles by absorbing water vapor (Tie et al., 2005) to become larger size particles. As a result, the larger particles enhance the scattering of sunlight, and lead to higher reduction of visibility. Figure 10 shows that prior the Fog-1 period, the measured visibility ranged from 600 to $1500 \mathrm{~m}$. The humidity ranged from 55 to $85 \%$ during the period. At the beginning of the period (from 12:00 LT to 12:40 LT, 5 November), the humidity was relatively low (55 to $65 \%$ ), and the visibility was relatively high $(1200-1500 \mathrm{~m})$. By contrast, at the end of the period (from 12:40 LT to 24:00 LT, 5 November), the humidity was rapidly increased from 60 to $80 \%$, and the visibility was significantly decreased from 1500 to several hundred meters. This result suggests that under heavy aerosol conditions, the hygroscopic growth of aerosols significantly affected the measured visibility. In or- der to quantify the individual contributions of the concentrations of aerosol particles (in dry state) and the hygroscopic growth of aerosol particles to the range of visibility, two calculations of the hygroscopic growth of aerosol particles with different humidity were conducted. The first calculation used a fixed humidity (40\%). In this case, the variability of the calculated visibility was only determined by the variability of aerosol concentrations. The calculated visibility in this case is consistently higher than the measured value (see Fig. 10). For example, the averaged visibility of the calculation is about $3236 \mathrm{~m}$, while the measured visibility is as low as $1657 \mathrm{~m}$. Unlike the measured visibility variability (higher at the beginning of the period and lower at the end of the period), the calculated visibility with fixed humidity cannot simulate the variability of measured visibility, suggesting that the measured variability of visibility was not determined by the aerosol variations, and was mainly due to the strong variation of humidity. In the second calculation, when the measured humidity was taken into account for the calculation, the calculated visibility was closed to the measured values, especially at the end of the period, in which the relative humidity was high (around $80 \%$ ). For example, the averaged visibility of the calculation at the end period (from 16:13 LT to 24:00 LT, 5 November) is about $1044 \mathrm{~m}$ compared with the measured value of $1200 \mathrm{~m}$. This calculation suggests that hygroscopicity of aerosols plays important roles for the reduction of visibility, especially during heavy aerosol loading conditions. However, at the beginning of the period, the calculated visibility was higher than the measured value. The calculated visibility was generally higher than $2000 \mathrm{~m}$, while the measured value ranged from 1200 to $1500 \mathrm{~m}$. This calculation indicates that the rate of hygroscopicity suggested by Yan et al. (2009) is underestimated under low humidity condition (less than $60 \%$ ) and is consistent to the measurement under high humidity condition (greater than $60 \%$ ).

\section{Summary}

The NCP region is one of the regions with very heavy aerosol loadings, and haze and fog events are frequently occurred in this region. In this study, a long-term trend of fog and haze over the NCP region during the past 56 years is analyzed to study the effect of aerosol loadings on the formations of haze and fog, especially under high aerosol loadings. In order to understand the detailed interaction between aerosol particles and the formations of haze and fog, a field measurement was conducted and measured result is analyzed in this study. During the experiment, a dense fog/haze event was occurred over the NCP region between 5 to 8 November, 2009, producing extremely low visibility. The in-suite measurement of meteorological parameters (such as surface winds, temperature, relative humidity, etc) and microphysical parameters of aerosol particles and fog droplets (such as the number density, the radius of aerosol particles and fog droplets) were 
measured and analyzed. The results are summarized as the follows:

1. The haze day occurrence over the NCP region in the past 56 years experienced a rapidly transition period. For example, before 1970, the haze days remained in a constant value (20-30 days $\mathrm{yr}^{-1}$ ), and the haze days started to increase in 1980. After 1980, the haze days remained a high values $50-100$ days $\mathrm{yr}^{-1}$.

2. There was a nonlinear relationship between the occurrences of haze and fog. When the haze day occurrences were lower than 40 days $\mathrm{yr}^{-1}$, the occurrences of fog was strongly proportional to the occurrences of haze day. By contrast, when the haze day occurrences were very high, the occurrence of fog were not sensitive to the occurrences of haze. For example, when the haze day occurrences were larger than 75 days $\mathrm{yr}^{-1}$, the occurrences of fog were remained a near constant value $\left(20\right.$ days $\left.\mathrm{yr}^{-1}\right)$.

3. During the fog periods, the visibility was strongly affected by the occurrences of fog droplets, which produced extremely low visibility (less than $100 \mathrm{~m}$ ). However, during the haze period, the hygroscopic of aerosols played an important role for the reduction of visibility, especially during heavy aerosol loading conditions. The calculated visibility with the hygroscopic growth of aerosol is consistent with measured visibility when relative humidity is high $(60-80 \%)$. However, the calculated visibility is larger than the measured visibility when relative humidity is low (less than $60 \%$ ), suggesting the rate of hygroscope is underestimated in this study under low humidity condition.

Acknowledgements. This research is partially supported by National Natural Science Foundation of China (NSFC) under Grant No. 40905060; The National Basic Research Program of China(2011CB403401); China Meteorological Administration (CMA) under Grant No. GYHY200806001-4. The project of scientific and technological new star of Beijing under Grant No. 2010 B029.

Edited by: X. Tie

\section{References}

Bian, H., Han, S. Q., Tie, X., Shun, M. L., and Liu, A. X.: Evidence of impact of aerosols on surface ozone concentration: a case study in Tianjin, China, Atmos. Environ., 41, 4672-4681, 2007.

Charlson, R. J., Lovelock, J. E., Andreae, M. O., and Warren, S. G.: Oceanic phytoplankton, atmospheric sulfur, cloud albedo and climate, Nature, 326, 655-661, 1987.
Charlson, R. J., Schwartz; S. E., Hales, J.M., Cess, R. D. J., Coakley, A., Hansen, J .E., and Hofmann, D. J.: Climate forcing by anthropogenic aerosol, Science, 255, 423-430, 1992.

Deng, Z. Z., Zhao, C. S., Ma, N., Liu, P. F., Ran, L., Xu, W. Y., Chen, J., Liang, Z., Liang, S., Huang, M. Y., Ma, X. C., Zhang, Q., Quan, J. N., Yan, P., Henning, S., Mildenberger, K., Sommerhage, E., Schäfer, M., Stratmann, F., and Wiedensohler, A.: Size-resolved and bulk activation properties of aerosols in the North China plain: the importance of aerosol size distribution in the prediction of CCN number concentration, Atmos. Chem. Phys. Discuss., 11, 1333-1366, doi:10.5194/acpd-111333-2011, 2011.

Deng, X. J., Tie, X., Wu, D., Zhou, X. J., Tan, H. B., Li, F., and Jiang, C.: Long-term trend of visibility and its characterizations in the Pearl River Delta Region (PRD), China, Atmos. Environ., 42, 1424-1435, 2008.

Han, S. Q., Bian, H., Tie, X., Xie, Y., Sun, M., and Liu, A.: Impact measurements of nocturnal planetary boundary layer on urban air pollutants: from a 250-m tower over Tianjin, China, J. Hazard. Mater., 162, 264-269, 2009.

Gultepe, I., Pearson, G., Milbrandt, J. A., Hansen, B., Platnick, S., Taylor, P., Gordon, M., Oakley, P., and Cober S.G.: The fog remote sensing and nodeling field project, B Am. Meteorol. Soc., 90(3), 341-359, 2009.

Guo X., Zheng, S., and Wang, J.: Field tests and measurement accuracy of automatic weather stations (AWS), J. Applied Meteorology (in Chinese), 5(22), 176-183, 1994.

Jacobson, M. Z.: Strong radiative heating due to the mixing state of black carbon in atmospheric aerosols, Nature, 409, 695-697, 2001.

Puustinen, A., Hämeri, K., Pekkanen, J., Kulmala, M., de Hartog, J., Meliefste, K., ten Brink, H., Kos, G., Katsouyanni, K., Karakatsani, A., Kotronarou, A., Kavouras, I., Meddings, C., Thomas, S., Harrison, R., Ayres, JG., van der Zee, S., and Hoek, G.: Spatial variation of particle number and mass over four European cities, Atmos Environ., 41, 6622-6636, 2007.

Ramanathan, V. and Vogelmann, A. M.: Greenhouse effect, atmospheric solar absorption, and the Earth's radiation budget: from the Arrhenius - Lanely era to the 1990s, Ambio, 26(1), 38-46, 1997.

Ramanathan, V., Crutzen, P.J., and Kiehl, J.T.: Aerocols, climate, and the hydrological cycle, Science, 294, 2119-2124, 2001.

Seinfeld, J. and Pandis, S.: Atmospheric Chemistry and Physics, Wiley, New York, USA, 1998.

Tegen, I., Koch, D., Lacis, A. A., and Sato, M.: Trends in tropospheric aerosol loads and corresponding impact on direct radiative forcing between 1950 and 1990: a model study, J. Geophys. Res., 105, 26971-26990, 2000.

Tie, X., Madronich, S., Walters, S., Edwards, D. P., Ginoux, P., Mahowald, N., Zhang, R. Y., Lou, C., and Brasseur, G.: Assessment of the global impact of aerosols on tropospheric oxidants, J. Geophys. Res., 110, D03204, doi:10.1029/2004JD005359, 2005.

Tie, X., Wu, D., and Brasseur, G.: Lung Cancer Mortality and Exposure to Atmospheric Aerosol Particles in Guangzhou, China, Atmos. Environ., 43, 2375-2377, 2009.

Wu, D., Tie, X., Li, C. C., Ying, Z. M., Lau, A. K., Huang, J., Deng, X. J., and Bi, X. Y.: An extremely low visibility event over the Guangzhou region: a case study, Atmos. Environ., 39, 6568-6577, 2005. 
Wu, D.: A discussion on difference between haze and fog in city, Meteorology (in Chinese), 32, 9-15, 2006.

Vautard, R., Yiou, P., and Oldenborgh, G.: Decline of fog, mist and haze in Europe over the past 30 years, Nat. Geosci., doi:10.1038/NGEO414, 2009.

Yan, P., Pan, X., Tang, J., Zhou, X., Zhang, R., and Zeng, L.: Hygroscopic growth of aerosol scattering coefficient: A comparative analysis between urban and suburban sites at winter in Beijing, Particuology, 7, 50-60, 2009.
Zhang, Q., Ma, X., Tie, X., Huang, M., and Zhao, C.: Vertical Distributions of Aerosols under Different Weather Conditions: Analysis of In-situ Aircraft Measurements in Beijing, China, Atmos. Environ., 43, 5526-5535, 2009.

Zhang, Q., Quan, J., Tie, X., Huang, M., and Ma, X.: Impact Aerosol Particles on Cloud Formation: Aircraft Measurements in Beijing, China, Atmos. Environ., 45, 665-672, 2011. 